\title{
Representasi Komodifikasi Simbol Religi dalam Iklan Wardah
}

\author{
Aulia Kholqiana (Penulis Korespondensi) \\ Program Studi Ilmu Komunikasi, Universitas Muhammadiyah Yogyakarta, Indonesia \\ kholqianaaa@gmail.com \\ Qoyyum Fauzianin \\ Program Studi Ilmu Komunikasi, Universitas Muhammadiyah Yogyakarta, Indonesia \\ Fauzianin2000@gmail.com \\ Shafa Tasya Azzahra \\ Program Studi Ilmu Komunikasi, Universitas Muhammadiyah Yogyakarta, Indonesia \\ shafatasyazzhr@gmail.com \\ Diserahkan: 05 Mei 2020; Direvisi: 06 Oktober 2020; Diterima: 10 Oktober 2020
}

\begin{abstract}
As is known to the public, Wardah's advertisements always emphasize beauty products with halal certification. This emphasis is actually a form of commodification in the delivery of advertising messages. This study discusses the commodification of religion contained in Wardah Tone Up Cream advertisements. The advertisement mentions the halal claim by starring a woman in hijab as a symbol of religiosity for Muslim women. The method used in this research is descriptive qualitative with a critical paradigm. Operationally, the research method used is semiotics. The results show that Wardah's advertisements show three forms of religious commodification in advertisements labeled halal, first is the use of Islamic iconography (depiction of identity) of Islam, second is the use of influential figures, and the third is the use of texts or contents of advertisements with Islamic messages that are away from its use.

Keywords: Wardah Ads, Halal Products, Commodification
\end{abstract}

\begin{abstract}
Abstrak
Sebagaimana diketahui publik, iklan Wardah selalu menekankan produk kecantikan dengan sertifikasi halal. Penekanan tersebut sebenarnya merupakan bentuk komodifikasi dalam penyampaian pesan iklan. Penelitian ini membahas tentang komodifikasi agama yang terdapat pada iklan Wardah Tone Up Cream. Iklan tersebut menyebutkan klaim halal dengan dibintangi perempuan berhijab sebagai simbol religiusitas bagi kalangan muslimah. Metode yang digunakan dalam penelitian ini adalah deskriptif kualitatif dengan paradigma kritis. Secara operasional, metode penelitian yang digunakan adalah semiotika. Hasil penelitian menunjukkan bahwa iklan Wardah menunjukan adanya tiga bentuk komodifikasi agama dalam iklan berlabel halal, pertama adalah pemanfaatan ikonografi (pengambaran identitas) islami, kedua adalah penggunaan tokoh yang berpengaruh, dan yang ketiga adalah pengunaan teks-teks ataupun isi dari iklan dengan pesan islami yang jauh dari penggunaanya.

Kata Kunci: Iklan Wardah, Produk Halal, Komodifikasi
\end{abstract}

\section{PENDAHULUAN}

Sejak lama, iklan telah menjadi berita atau informasi yang berisi pesan persuasif mengenai suatu produk agar menarik untuk dibeli. Media yang digunakan dalam proses penyampaian iklan saat ini terus berkembang dan semakin beragam. Dewasa ini, iklan tidak hanya menjadi media promosi suatu produk saja, namun juga memunculkan banyak persoalan sosial dan kebudayaan. Informasi-informasi melalui iklan juga mempengaruhi banyak hal seperti pemahaman, persepsi, dan tingkah laku masyarakat.

Produk Wardah menjadi salah satu produk kosmetik dan kecantikan dengan label halal yang saat ini menjadi produk kecantikan yang digemari oleh perempuan di Indonesia. Kehalalan suatu produk, tidak terbatas pada produk kecantikan telah menjadi kebutuhan banyak orang khususnya kalangan muslim yang dominan sebagai konsumen terbesar di Indonesia. Dalam hal ini, produk kosmetik dikatakan halal 
jika diambil dari bahan baku yang aman dan sesuai syariat islam. Hal ini dapat dilihat dari sumber kosmetik yang digunakan, apakah binatang, tanaman, atau tambang. Dalam ketentuan Majelis Ulama Indonesia (MUI), konsep halal meliputi jaminan kualitas dan keamanan sehingga klaim halal pada produk Wardah bermaksud untuk menunjukkan bahwa produk tersebut terjamin kualitas dan keamanannya.

Berangkat dari fenomena tersebut, penelitian ini dimaksudkan untuk mengetahui bagaimana representasi komodifikasi simbol religi pada produk Wardah. Di antara berbagai iklan produk kecantikan yang berasal dari Indonesia, Wardah merupakan produk kecantikan yang sangat konsisten menunjukan identitas halal, mulai dari bahan bakunya hingga cara pengemasannya. Dalam hal ini, Wardah memanfaatkan permintaan pasar yaitu produk halal dengan pertimbanga Indonesia memiliki peluang besar menjadi pusat ekonomi halal. Wardah sendiri ingin mengajak masyarakat Indonesia agar memakai produk halal sebagai gaya hidup. Hal tersebut dibuktikan dengan model iklan Wardah yang tidak semuanya memakai hijab.

Dalam menentukan produk yang akan dipilih, konsumen tentunya akan mencari tahu mengenai produk yang dibutuhkan. Pengetahuan mengenai hal tersebut kemudian menjadi dasar pembelian produk yang dipilihnya. Berdasarkan penelitian yang dilakukan oleh Rahman et al. (2015) pengetahuan yang dimiliki konsumen atas produk tertentu mempunyai pengaruh besar terhadap intensi dan keputusan sang konsumen dalam memilih sebuah produk.

Di Indonesia sendiri, penduduk muslim menjadi penduduk dengan jumlah yang paling banyak. Kebutuhan konsumen berdasarkan kriteria kehalalan menjadi prioritas bagi konsumen beragama Islam. Dalam konteks ini, agama menjadi bagian yang tak terpisahkan dari individu dan masyarakat yang dijadikan komoditas untuk meraih keuntungan (Rozaki, 2013). Di sini dapat kita lihat bahwa pesan iklan disampaikan sebagai upaya kapitalisme mengubah nilai fungsi (use value) atau guna menjadi sebuah nilai tukar (exchange value) untuk tujuan komersial, atau yang biasa disebut dengan komodifikasi (Mosco, 2010).

\section{KERANGKA TEORI} SEMIOTIKA

Semiotika meneliti tentang tanda (sign) yang terdiri dari dua aspek, yaitu penanda (signifier), dan petanda (signified). Penanda dapat dimengerti sebagai bentuk/wujud fisik. Penanda dapat berupa bunyi, gambar, huruf, visual, dan sejenisnya. Sedangkan petanda adalah konsep atau arti dari apa yang ditandai. Keduanya memiliki relasi yaitu bersifat "diada-adakan" yang berarti tidak terdapat relasi yang sifatnya alamiah antara penanda dan petanda. Namun demikian, relasi yang bersifat "diada-adakan" tersebut terikat oleh konvensi atau struktur. Secara etimologis, Saussure menyebutkan bahwa semiotika sebagai ilmu yang mengkaji tentang tanda sebagai bagian dari kehidupan sosial (Piliang, 2003). Semiotika kemudian dielaborasi sebagai hubungan tripartit yakni tanda (sign) yang merupakan gabungan dari penanda (signifier) dan petanda (signified) (Fiske \& Hartley, 1996).

Pemikiran Saussure tersebut kemudian dikembangkan oleh Roland Barthes dengan memberi telaah pada interaksi antara teks dengan pengalaman personal dan kultural penggunanya. Gagasan Barthes ini dikenal dengan tatanan penandaan (order of signification), yang mencakup primary signification atau denotasi (makna sebenarnya sesuai kamus) dan secondary signification atau konotasi (makna ganda yang lahir dari pengalaman kultural dan personal). Makna konotasi inilah yang kemudian berkembang menjadi mitos. Dalam penelitian ini, penulis berusaha melakukan analisis semiotika, mulai dari primary signification hingga secondary signification pada iklan Wardah Perfect Bright Tone Up Cream. 


\begin{tabular}{c|c}
\hline $\begin{array}{c}\text { Signifier } \\
\text { (Penanda) }\end{array}$ & $\begin{array}{c}\text { Signified } \\
\text { (Petanda) }\end{array}$ \\
\hline \multicolumn{2}{c}{$\begin{array}{c}\text { Denotatif Sign } \\
\text { (Tanda Denotatif) }\end{array}$} \\
\hline \multicolumn{2}{c}{ Connotatif Signifier } \\
(Penanda Konotatif) & $\begin{array}{c}\text { Connotatif Signified } \\
\text { (Petanda Konotatif) }\end{array}$ \\
\hline \multicolumn{2}{c}{ Connotatif Sign } \\
(Tanda Konotatif)
\end{tabular}

Gambar 1. Pemaknaan tanda dalam semiotika Roland Barthes (Sobur, 2004)

\section{REPRESENTASI}

Representasi adalah produksi makna melalui bahasa. Representasi adalah proses bagaimana kita memberi makna pada sesuatu melalui bahasa. Untuk mempresentasikan juga berarti menyimbolkan, untuk mewakili, menjadi contoh, atau menjadi pengganti dari sesuatu (Hall, 1997). Komodifikasi mengacu pada proses mengubah nilai guna menjadi nilai tukar, mengubah produk yang nilainya ditentukan oleh kemampuan mereka untuk memenuhi individu dan kebutuhan sosial ke dalam produk yang nilainya ditentukan oleh harga pasar mereka (Mosco, 2009). Komodifikasi biasa diartikan sebagai kegiatan pengelola media dalam memperlakukan pesan sebagai komoditas yang bisa menyenangkan khalayak, mengundang para pemasang pengiklan, dan memperpanjang bisnis media, (Halim, 2013).

\section{KONSEP HALAL}

Kata halal (حَلَّل, halāl, halaal) adalah istilah bahasa Arab dalam agama Islam yang berarti diizinkan" atau "boleh". Secara etimologi, halal berarti hal-hal yang boleh dan dapat dilakukan karena bebas atau tidak terikat dengan ketentuan-ketentuan yang melarangnya. Menurut Qardawi (2007) Istilah halal dalam kehidupan sehari-hari sering digunakan untuk makanan ataupun minuman yang diperolehkan untuk dikonsumsi menurut syariat Islam. Sedangkan dalam konteks yang lebih luas istilah halal merujuk kepada segala sesuatu baik tingkah laku, aktifitas, maupun cara berpakaian dan lain sebagainya yang diperbolehkan atau diizinkan oleh hukum Islam. Label halal merupakan pencantuman tulisan atau pernyataan halal pada kemasan produk untuk menunjukkan bahwa produk yang dimaksud berstatus sebagai produk halal. Label halal sendiri diperoleh setelah mendapatkan sertifikat halal. Sertifikat halal ini merupakan syarat untuk mendapatkan ijin pencantuman label halal pada kemasan produk dari instansi pemerintah yang berwenang. Adapun yang dimaksud dengan produk halal adalah produk yang memenuhi syarat kehalalan sesuai dengan syariat Islam. Produk kosmetik memang tidak dimakan dan masuk ke dalam tubuh. Oleh karena itu, kosmetik biasanya dikaitkan dengan masalah suci atau najis. Dalam hal ini, produk tersebut bisa dikatakan haram jika produk kosmetik tersebut mengandung bahan-bahan najis, seperti turunan hewan (kolagen) ataupun bagian dari tubuh manusia, misalnya plasenta. Kosmetik halal juga tidak boleh mengandung alkohol, karena alkohol/khamer tidak diperbolehkan masuk dalam suatu produk yang dikonsumsi.

\section{METODE PENELITIAN}

Dalam penelitian ini, metode yang digunakan adalah deskriptif kualitatif dengan paradigma kritis. Secara lebih operasional, penelitian ini menggunakan metode semiotika untuk menganalisis objek penelitian berupa Iklan Wardah Perfect Bright Tone Up Cream yang tayang pada tahun 2019 dibintangi oleh Ayana Jihye Moon, seorang artis dari Korea yang saat ini menetap di Indonesia dan menjadi seorang muslim dan berhijab. Iklan ini berdurasi 31 detik yang di dalam narasinya disebutkan bahwa produk tersebut merupakan tren kecantikan Korea bersertifikat halal. Oleh karenanya, iklan tersebut dibintangi oleh artis Korea yang berhijab. Adapun objek penelitian ini dianalisis dengan 
menggunakan analisis semiotika Roland Barthes yang mengembangkan pemikiran dari Ferdinand De Saussure.

\section{HASIL DAN PEMBAHASAN}

REPRESENTASI SIMBOL RELIGI DALAM BUDAYA KONSUMEN

Berdasarkan hasil analisis, simbol halal yang notabene merupakan simbol religi dalam produk Wardah ini memiliki pengaruh yang cukup besar dalam mempengaruhi konsumen. Dalam pandangan penulis, komodifikasi religi dalam produk Wardah yang disajikan dengan klaim halal serta dibintangi oleh perempuan berhijab telah berhasil mempengaruhi pelanggan khususnya masyarakat muslim Indonesia. Wardah sendiri merupakan produk kecantikan yang sangat konsisten menunjukan bahwa produknya merupakan produk yang halal, mulai dari bahan baku hingga cara pengemasannya. Dalam hal ini, wardah memanfaatkan permintaan pasar yaitu produk halal dengan pertimbangan Indonesia memiliki peluang besar untuk menjadi pusat ekonomi halal.

Pengetahuan yang dimiliki oleh konsumen terkait dengan hal-hal yang dilarang dan diperbolehkan (halal dan haram) dalam syariat Islam berhasil mempengaruhi sikap terhadap produk kosmetik halal. Semakin besar pengetahuan yang dimiliki oleh konsumen terkait dengan permasalahan halal dan haram, maka semakin besar pula sikap dan responnya terhadap produk kosmetik yang halal. Tidak hanya pengetahuan halal haram konsumen yang diandalkan, Wardah juga telah mengkomodifikasi agama Islam dalam iklan televisinya untuk mewancanakan produk kosmetik halal. Salah satu yang dilakukan oleh pengiklan adalah memanfaatkan perempuan berhijab sebagai salah satu bintang iklan (Maulidiyah, 2018).

\section{REPRESENTASI PEREMPUAN IDEAL DAN RELIGIUS DALAM IKLAN WARDAH}

Pengiklan umumnya memanfaatkan bintang iklan yang sesuai dengan representasi ideal bagi produk yang akan diiklankan. Tidak terkecuali iklan produk kecantikan seperti Wardah yang mana memanfaatkan perempuan berhijab sebagai salah satu bintang iklannya. Iklan adalah sistem tanda terorganisir menurut kode-kode yang merefleksikan nilai- nilai tertentu, sikap, dan juga keyakinan tertentu. Setiap pesan dalam iklan memiliki makna yang dinyatakan di dalam isi iklan. Dengan demikian, semiotika menjadi metode yang sesuai untuk mengetahui kontruksi makna yang terjadi dalam iklan dengan menekankan peran sistem tanda dengan konstruksi realitas, maka melalui semiotika ideology-ideologi di balik iklan bisa dibongkar (Djamereng, 2018).

Dalam iklan Wardah, iklan Perfect Bright Tone Up Cream sendiri dibintangi Ayana Jihye Moon yang merupakan perempuan asal Korea yang saat ini menetap di Indonesia dan menjadi Muallaf. Dari hal ini dapat dilihat bahwa Ayana Jihye dijadikan representasi standar cantik wanita Korea yang saat ini juga menjadi standar cantik di Indonesia. Standar cantik yang dimaksud adalah kulit putih mulus, kulit kencang, cerah dan tanpa keriput. Pandangan tersebut mengisyaratkan bahwa perempuan dengan warna kulit putih merupakan dambaan banyak kaum perempuan di Indonesia. Hal ini jelas merupakan pasar potensial bagi produk-produk pemutih kulit. Caranya yaitu dengan menampilkan imaji bahwa yang putih adalah yang cantik sehingga mayoritas yang berkulit sawo matang menjadi ingin memiliki kulit seperti sejumlah minoritas (Winarni, 2010).

Makna dari setiap tanda/simbol yang terkandung dalam pesan visual dari iklan tersebut menurut teori Roland Barthes bisa dikaji melalui dua tahapan yaitu pertama makna yang dianalisa secara denotatif dan kedua adalah secara konotatif (Walisyah, 2007). Dimana denotatif adalah pendekatan yang dilakukan untuk memberikan makna terhadap pesan visual pada tayangan Iklan Televisi Wardah yang dibintangi oleh Ayana Jihye tersebut dengan cara menjelaskan apa adanya sesuai dengan yang digambarkan pada tayangan iklan tersebut tanpa ada penambahan makna tertentu. 
Setidaknya, terdapat tiga bentuk komodifikasi agama dalam iklan berlabel halal, di antaranya adalah pertama pemanfaatan ikonografi (pengambaran identitas) islami yang digunakan untuk memasarkan produk-produk tertentu kepada konsumen. Kedua, adalah penggunaan tokoh yang berpengaruh yaitu ustadz/ustadzah ataupun bintang iklan yang islami (Abimono, 2018). Dipilihnya orang-orang berpengaruh pada iklan Wardah yang diperankan oleh Ayana Jihye dimaksudkan menarik konsumen. Adapun yang ketiga adalah pengunaan teks-teks ataupun isi dari iklan dengan pesan islami yang jauh dari penggunaanya.

Melalui media massa khususnya televisi, perempuan dijadikan sebagai komoditi. Secara perlahanlahan media membentuk opini publik, keyakinan individu, dan bahkan persepsi diri pribadi. Dalam hal ini, media mempunyai dampak yang sangat berarti pada proses sosialisasi masyarakat luas dan turut membentuk pemikiran dan ideologi (Cholidah, 2015). Pada akhirnya, pengiklan pun menampilkan seideal mungkin perempuan yang menjadi bintang di iklan ini, agar tertanam pada pikiran masyarakat bahwa mereka harus seperti bintang di iklan tersebut agar bisa menjadi perempuan idea yang kemudian juga bertujuan untuk menarik calon konsumen agar membeli produk Wardah tersebut.

\section{KESIMPULAN}

Sebagai produk kosmetik yang berklaim halal, Wardah menampilkan wanita berhijab lengkap dengan standar cantik yang selama ini terbangun di masyarakat yaitu kulit putih mulus, kencang, cerah, dan tidak keriput sebagai representasi perempuan ideal dan religius yang ditampilkan di iklan Wardah. sehingga membentuk pandangan bahwa perempuan yang ditampilkan seperti dalam iklan Wardah adalah gambaran perempuan ideal yang menjadi dambaan perempuan lainnya. Hal ini menyebabkan perempuan Indonesia yang mayoritas berkulit sawo matang ingin memiliki kulit sejumlah minoritas yang digambarkan dalam iklan Wardah tersebut.

Iklan Wardah menunjukan adanya tiga bentuk komodifikasi agama dalam iklan berlabel halal, diantaranya adalah pertama pemanfaatan ikonografi (pengambaran identitas) Islami yang digunakan untuk memasarkan produk-produk tertentu kepada konsumen. Kedua, adalah penggunaan tokoh yang berpengaruh yaitu ustadz/ustadzah ataupun bintang iklan yang Islami. Ketiga pengunaan teks-teks ataupun isi dari iklan dengan pesan Islami yang jauh dari penggunaanya.

\section{PERSANTUNAN}

Terima kasih kepada Dr. Fajar Junaedi yang telah membimbing proses riset dalam mata kuliah Kajian Kritis Iklan di Program Studi Ilmu Komunikasi UMY, selama satu semester genap tahun akademik 2019/2020 yang menghasilkan luaran berupa artikel ini.

\section{REFERENSI}

Abd Rahman, A., Asrarhaghighi, E., \& Ab Rahman, S. (2015), Consumers and Halal cosmetic products: knowledge, religiosity, attitude and intention. Journal of Islamic Marketing, 6(1), 148163.

Aertsens, J. M. (2011). Influence of Subejective and Objective Knowledge on Attitude, Motivations and Consumption of Organic Food. British Food Journal, 113(11), 1353-1378.

Aryasatya, A. B. A. (2018). Komodifikasi Agama Melalui Iklan Televisi (Studi Kasus Iklan Televisi Berlabel Halal). Jurnal Pustaka Ilmiah, 4(1), 515-523.

Baskoro, I. S., \& Ahmad, B. A. (2014) Komodifikasi Dan Komunikasi: Mengkaji Media Dan Budaya dalam Dinamika Globalisasi. Jakarta: Pustaka Obor Indonesia.

Cholidah, L. I. (2015). Citra Tubuh Ideal dalam Iklan Televisi. Jurnal ANIDA, 14(2), 417-430.

Djamereng, A. (2018). Analisis Semiotika Pada Iklan Di Televisi (Iklan Wardah dan Iklan Total Almeera). Jurnal Al-Khitabah: Jurnal Komunikasi \& Penyiaran Islam, 4(1), 1-16. 
Halim. (2013). Post Komodifikasi Media. Yogyakarta: Jalasutra.

Hall, S. (1997). Representation:Cultural Representation and Signifying Practice. London : SAGE.

Larasati, A., Hati, S. R. R. H., \& Safira, A. (2018). Religiusitas dan Pengetahuan Terhadap Sikap dan Intensi Konsumen Muslim untuk Membeli Produk Kosmetik Halal. Esesnsi: Jurnal Bisnis dan Manajemen, 8(2), 105-114.

Mosco, V. (2009). The Political Economi of Communication. London: SAGE.

Prameswari, N. (2015). Di Balik Topeng Maskulinitas Iklan Rokok: Kritik Terhadap Iklan Rokok A Mild Media Outdoor Versi Berani Takut. Imaji: Jurnal Seni dan Pendidikan Seni, 12(2), 39-54.

Qardhawi, Y. (2007). Halal dan Haram dalam Islam. Surakarta: Era Intermedia.

Walisyah, T. (2017) Analisis Semiotik Iklan Televisi Wardah Versi Goes to Paris. Komunikologi: Jurnal Pengembangan Ilmu Komunikasi dan Sosial, 1(2), 28-51.

Widyaningrum, P. W. (2019). Pengaruh Label Halal, Kesadaran Halal, Iklan, dan Celebrity Endorser terhadap Minat Pembelian kosmetik melalui variabel Persepsi sebagai Mediasi (Studi Pada Civitas Akademika Universitas Muhammadiyah Ponorogo). Jurnal Ekonomi dan Manajemen, 2(2), 74-97.

Winarni, R. W. (2010). Representasi Kecantikan Perempuan dalam Iklan. DEIKSIS, 2(2), 134-152. 